\title{
NEUROSCIENCE
}

\section{The ears have it}

\section{Andrew King enjoys a personal account of the impact of sound on life, evolution and the brain.}

$\mathrm{W}$

hy does scraping your fingernails down a blackboard evoke such a strong reaction? This is one of many questions tackled in Seth Horowitz's The Universal Sense. Hearing provides us with an incredibly rich source of information about the world and, through speech and music, plays a central part in communication. In this enjoyable book, Horowitz describes the ingenious ways in which different species produce and respond to sound, and how these have shaped the creatures' acoustic environments.

Horowitz begins by asking how noisy Earth might have been before the emergence of the first creatures capable of hearing the primordial sounds of rain, volcanoes and meteorite impacts, and how life changed this soundscape. He then highlights the characteristic features of everyday sounds, such as voices and birdsong, and explains how the acoustic properties of buildings, road surfaces and other environmental objects influence what we actually hear.

Moving on to the auditory abilities of different species, Horowitz looks at the challenge of hearing underwater, where sound travels much faster than it does through air. He also details the specializations that have evolved in frogs and bats for producing and listening to verylow- or very-highfrequency sounds, respectively.

After a brief overview of the organization of the hearing regions of the brain, Horowitz describes how effectively sounds can evoke emotional reactions or grab the listener's attention. Of course, any of our

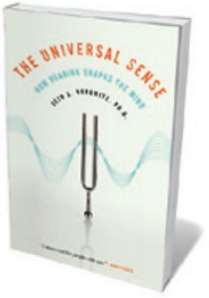

The Universal Sense: How Hearing Shapes the Mind SETH S HOROWITZ Bloomsbury: 2012 320 pp. $\$ 25.00$, $£ 15.99$ senses can achieve this, but acoustic signals, especially music, seem to have a particularly powerful influence on our emotions and memories. This reflection leads neatly into a chapter on the challenge of understanding our response to music. Whether we find a piece of music pleasant or not is much more than a matter of the physics of sound. Horowitz emphasises the need to take account of both cultural and individual differences when attempting to explain our musical preferences, and offers an appropriate critique of studies that claim listening to

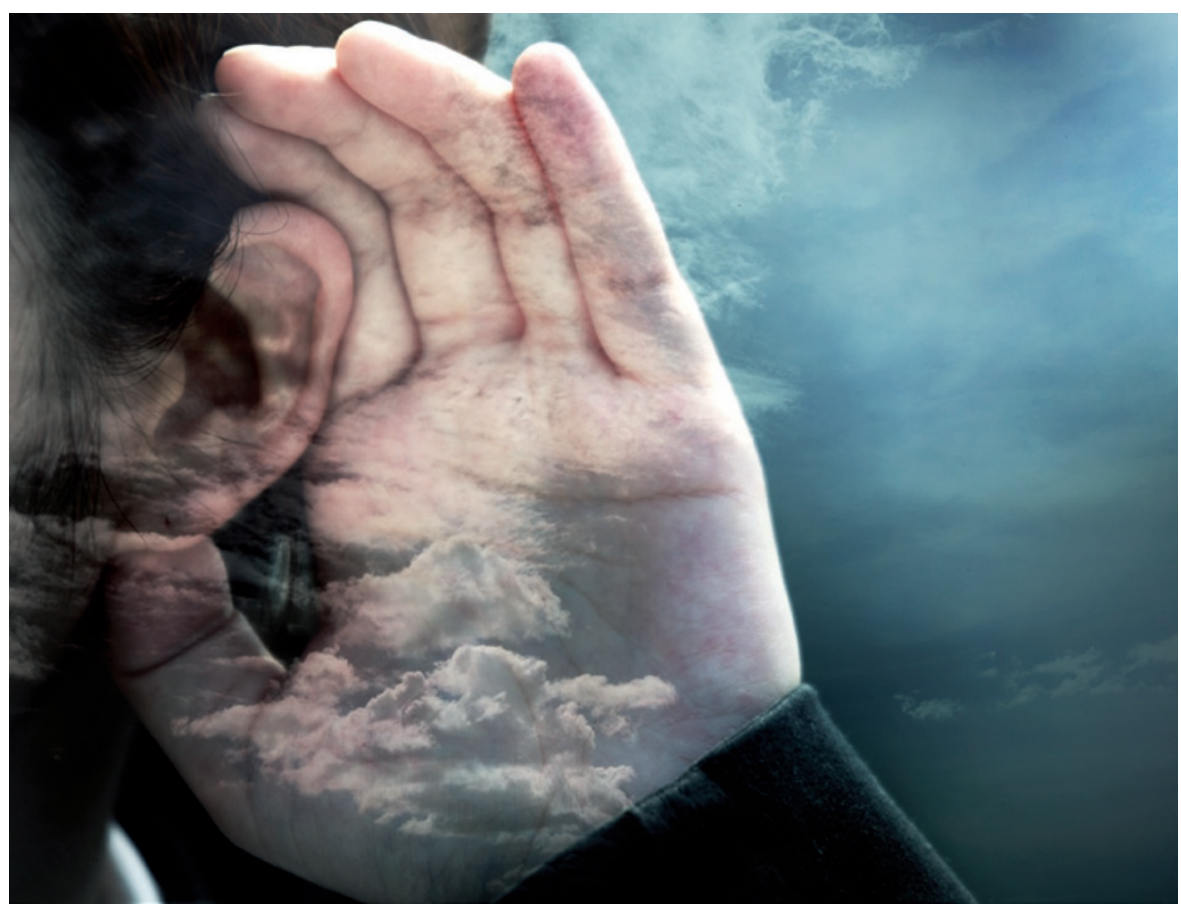

Sounds can have powerful influences on our emotions and memories.

Mozart can boost your intelligence.

Horowitz looks too at how the use of music and sound effects in entertainment and advertising often relies on principles of auditory perception that were in use long before we understood their biological basis. He discusses the body's reaction to silence and loud sounds, and how certain, often rhythmic, sounds can induce hypnosis and other mindaltering states. As the author points out, a truly silent environment doesn't really exist because sounds that are inaudible to humans can usually be heard easily by other species. Even in the absence of any sound sources, the acoustic properties of the environment influence our perceptions. This is demonstrated by the often unsettling experience of stepping into an anechoic chamber, where the walls suck out the reverberation and echoes that inhabit more typical rooms.

Horowitz's attention to the discomfiting side of the auditory world doesn't stop there. He goes on to consider how the more sinister applications of sound have been exploited in psychological warfare, as illustrated, for example, by the howl of German Stuka aircraft during their dive-bombing raids in the Spanish Civil War and the Second World War.

In the penultimate chapter, Horowitz speculates on the promise of future research, from the challenge of restoring hearing by regrowing the ear's sensory hair cells - which all too easily succumb to age, loud sounds and infection - to listening to the soundscapes of other planets. Finally, he celebrates what he calls the "song of the brain" itself: the distinctive chorus of clicks, signalling neural activity, that can be picked up over an audio monitor when an electrode is advanced into the brain. He speculates that the mind may emerge from this "neuronal orchestra" of activity across the brain much as music consists of - but is also so much more than - a collection of notes.

The Universal Sense is a clear, humorous, personal account, punctuated by numerous anecdotes from Horowitz's own experience as a scientist, electronic-music producer and sound designer. Although these link together the different sections of the book, their inclusion does skew the content towards the author's interests. The book's coverage of the neuroscience of hearing is patchy. For example, Horowitz says little about the possible neural basis for differences in musical or linguistic abilities. But this is not intended to be a textbook. Instead, by rooting his tale in familiar examples - such as that blackboard - Horowitz provides a fascinating insight into the remarkable impact that sound has on the workings of the brain.

Andrew J. King is a Wellcome Principal Research Fellow and professor of neurophysiology at the University of Oxford, $U K$.

e-mail: andrew.king@dpag.ox.ac.uk 